\title{
The Evolution of Responsible Gambling Policy and Practice: Insights for Asia from Australia
}

\author{
Nerilee Hing* \\ Centre for Gambling Education and Research, School of Tourism and Hospitality \\ Management, Southern Cross University, P.O. Box 157 Lismore, NSW 2480, \\ Australia \\ * Corresponding author; email: nerilee.hing@scu.edu.au
}

\begin{abstract}
This paper draws on the Australian experience of problem gambling and responsible gambling to provide insights for Asian jurisdictions currently experiencing significant expansion in gambling. Specifically, it draws on a lifecycle approach to issues management to explain the emergence of problem gambling as a significant social and public health issue in Australia. It then documents how gambling operators in Australia have responded to this issue through the development and implementation of responsible gambling measures. Four developmental stages of responsible gambling policy and practice in Australia are discussed, from an elementary stage of corporate citizenship through to engaged and innovative stages, and to the next stage of integration into the business of gambling. Current pressures are identified that may result in Australian gambling operators reaching the so-called transforming stage of corporate citizenship in responsible gambling, where more effective and targeted measures are implemented. Insights are drawn from the Australian experience, which may be of relevance to the future of responsible gambling in Asia. The embedding of responsible gambling in corporate culture and business practice appears to be facilitated by numerous specific measures. These include: appropriate legislation; leadership; structural changes; resources and support mechanisms outside of the organization; effective relationships with key stakeholders; dedicated management; supervisory positions; staff training; and accountability and transparent reporting within the organization.
\end{abstract}

Key words Australia - Asia - Corporate Citizenship - Problem Gambling . Responsible Gambling

\section{Introduction}

By the 1990s, problem gambling had emerged as a significant social and 
public health issue in Australia. The respective stance and actions of gambling operators, governments, pressure groups and the epistemic community had diverged substantially, leading to a widening gap between actual corporate behavior and that desired by influential stakeholders (Hing, 2002). When viewed in terms of the lifecycle of gambling as an issue, problem gambling emerged from the "zone of indifference" and the "zone of rejection" to the "zone of acceptance" (Barnard, 1938, p. 25), where it was recognised as an important issue requiring attention and action. One response to this issue has been the implementation of responsible gambling measures by gambling operators.

Since the late 1990s, responsible provision of gambling has itself evolved through sequential stages of corporate citizenship, from minimum compliance to integration into the business of gambling (Table 1). Each stage in this evolutionary process has varied along key dimensions, such as organizational commitment, strategic intent, stakeholder relationships, organizational structure, policy and practices, and stewardship. Although Australian gambling operators have changed their business practices over time to become more socially responsible providers of gambling, the pressure for further change remains.

This paper tracks these developments, drawing upon relevant research and other literature, and the author's experience in the development and evaluation of responsible gambling programs in Australia. The aim of the paper was to contribute to knowledge on the topic by adapting and applying a generic model of corporate citizenship to responsible gambling, based on selected evidence and examples. As Apostel (1961, p. 14) points out, models serve the purpose of explaining the systems they are models of and "explanation occurs so often, or nearly always, through model-building". This is because models provide a more easily comprehended and simplified view of the complex reality in a logical way. Explaining the triggers for and trajectory of corporate citizenship in responsible gambling as experienced in another jurisdiction (Australia) may assist its rapid adoption among gambling operators in Asia, through the recognition and application of underlying principles and conditions.

There are three main sections in this paper. The first section summarises previous analysis by the author, explaining the emergence of problem gambling as a corporate social issue in Australia. The second section provides an original analysis of developmental stages of responsible gambling policy and practice in that country. The third section offers some insights for Asian jurisdictions currently experiencing significant expansion in gambling operations, to facilitate policy development. The Australian experience is pertinent to use, as it was one of the first countries worldwide to respond to growing concerns about problem gambling through the establishment of responsible gambling programs (Volberg, 1998). The paper also highlights similarities and differences likely to influence whether responsible gambling in Asia will follow the same trajectory.

\section{Emergence of Problem Gambling as a Corporate Social Issue}

Australia has a long history as a nation of gamblers (Charlton, 1987). While problem gambling is not a recent phenomenon, it did not rise to prominence as a social issue until the 1990s (Hing, 2009). This reflects the fact that a social problem may exist 
Table 1. Stages of corporate citizenship in responsible gambling

\begin{tabular}{|c|c|c|c|c|c|}
\hline & Stage 1: Elementary & Stage 2: Engaged & Stage 3: Innovative & Stage 4: Integrated & Stage 5: Transforming \\
\hline $\begin{array}{l}\text { Stakeholder } \\
\text { relationships }\end{array}$ & $\begin{array}{l}\text { No or minimal } \\
\text { engagement }\end{array}$ & Only as necessary & Increased interaction & Mutual influence & $\begin{array}{l}\text { Partnerships \& multi- } \\
\text { organization alliances }\end{array}$ \\
\hline Structure & $\begin{array}{l}\text { No specified } \\
\text { responsible gambling } \\
\text { functions }\end{array}$ & $\begin{array}{l}\text { Some centralised } \\
\text { interest, little } \\
\text { diffusion through } \\
\text { organization }\end{array}$ & $\begin{array}{l}\text { Functional ownership of } \\
\text { responsible gambling }\end{array}$ & $\begin{array}{l}\text { Dedicated departments } \\
\text { \& positions, coordination } \\
\text { of responsible gambling } \\
\text { across the organization }\end{array}$ & $\begin{array}{l}\text { Mainstream, } \\
\text { permeates } \\
\text { organization }\end{array}$ \\
\hline
\end{tabular}

Note. Adapted from Mirvis, P. and Googins, B. "Stages of Corporate Citizenship". Copyright $\odot 2006$, by the Regents of the University of California. Reprinted from The California Management Review Vol. 48, No. 2. By permission of the Regents. 
objectively but that it only becomes an issue requiring management attention when defined as problematic to society by key stakeholders (Mahon \& Waddock, 1992). By the late 1990s, problem gambling had emerged as an issue demanding a response from organizations providing gambling services, especially gaming machines. It had acquired key features of corporate social issues - their impact is felt within the organization; there is contestability about organizational change demanded by stakeholders; and these stakeholder demands arise from "expectational gaps" between organizational behavior and that desired by these stakeholders (Wartick \& Mahon, 1994).

Hing's (2002) analysis of the emergence of problem gambling as a corporate social issue for gambling operators in Australia is now outlined. This provides a context for later analysis of the evolution of contemporary, responsible gambling policy and practice.

\section{Epistemic influences}

Until the 1970s, problem gambling received little attention from stakeholders. A reconceptualization of problem gambling by the epistemic community was instrumental in projecting problem gambling into the social and public health arenas. Early conceptualizations of frequent, heavy, uncontrolled gambling viewed the behavior as a mental disorder, addiction or extreme behavior. By the 1990s, experts in Canada, New Zealand and Australia had redefined problem gambling according to the harms it caused and as a public health issue (McMillen, 1997). This shifted the focus from individual gamblers with gambling problems to the broader population of gamblers. The accompanying expectation of this shift was that gambling providers and regulators should enact structural changes for improved harm minimization and consumer protection in gambling.

\section{Pressure group influences}

Until the early 1900s, opposition to gambling was framed mainly in terms of moral arguments advanced by the churches and conservative middle classes (Sylvan \& Sylvan, 1985). Later, in the 1970s-1990s, concern for gambling-related crime underpinned opposition to proposed casinos and gaming machines (Moffitt, 1974; Lusher, 1977; Connor, 1983; Wilcox, 1983; Street, 1991). Perceptions of gambling as socially disruptive and undermining the work ethic (Sylvan \& Sylvan, 1985) were later replaced by sociological analyses which presented gambling as a legitimate, natural leisure activity (McMillen, 1996a) and arguments against gambling which focused increasingly on its social impact (Hing, 2002). Pressure groups began to place responsibility for minimizing the harm associated with gambling squarely on the shoulders of government and gambling providers, with gamblers often depicted as victims of irresponsible, predatory practices (see for example submissions to the IPART's 1998 NSW Gaming Inquiry and the 1999 Productivity Commission Inquiry).

\section{Government influences}

In Australia, state governments preside over gambling policy, regulation and taxation. They generally agree on broad policy objectives of maximizing revenue, 
minimizing social impact, ensuring product integrity, and deterring criminal involvement (Productivity Commission, 1999). Differing prioritization of these sometimes-conflicting goals over time has influenced the emergence of problem gambling as a social issue.

By the 1990s, government gambling policy had evolved through three distinct shifts (McMillen, 1996b). Selective prohibition had dominated until the 1920s. This was followed by a "softening" in the government position up to the 1970s, as gambling gained new respectability through association with welfare purposes (McMillen, 1996b), specifically state lotteries, church and charity bingo, and machine gambling in some not-for-profit clubs. During the 1970s-1990s, gambling policy shifted to embrace market stimulation, expansion, competition and privatization (McMillen, 1996b). Governments' increased dependence on gambling taxes increased tension between their economic objectives and social responsibilities (McMillen, 1994, 1996b). The resulting "moral panic" (McMillen, 1998, p. 251) about the social effects of gambling reflected increasing divergence between government policy and public opinion.

\section{Gambling industry influences}

From the 1970s-1990s, gambling expenditure in Australia continued to rise (Tasmanian Gaming Commission, 2000), with many providers capitalizing on sympathetic government policies (Hing, 2009). This resulted in easy access to gambling, particularly to gaming machines, a proliferation of gambling options, the concentration of gambling venues in low socio-economic areas, and intense marketing (Hing, 2002). Economic imperatives far outweighed concern for social ramifications, reflected in industry rejection of problem gambling as an issue warranting its attention and resources (Hing, 2002, 2009). These factors heightened public concern for gambling-related harms and prompted calls for more socially responsible provision of gambling.

\section{Origins of responsible gambling measures}

By the late 1990s, problem gambling had emerged as a significant corporate social issue in Australia. Substantial gaps in expectations among the four stakeholder groups emanated from sustained divergence between industry and government policies and practices and stakeholder expectations for gambling reform. Resolving the issue required narrowing these gaps through substantive actions to address problem gambling. This ushered in measures, which are now collectively known as responsible gambling.

\section{Corporate Citizenship in Responsible Gambling: Developmental Stages}

Since the emergence of a public health approach to gambling, it has been generally agreed that responsible gambling aims to reduce the harms associated with gambling. Blaszczynski, Ladouceur, and Shaffer (2004, p. 308) defined responsible gambling as: "policies and practices designed to prevent and reduce potential harms associated with gambling; these policies and practices often incorporate a diverse range of interventions designed to promote consumer protection, community/ 
consumer awareness and education, and access to efficacious treatment".

These policies and practices have progressed through different stages of corporate citizenship. This reflects that, in systems of all types, there are distinct patterns of activity at different points of development and these activities typically become more sophisticated and complex as development progresses; further, the application of internal capabilities to environmental challenges tends to propel corporate citizenship forward (Mirvis \& Googins, 2004).

In relation to responsible gambling, Australia has witnessed substantial developments in gambling operator practices, from Mirvis and Googins' (2004) "elementary" stage of corporate citizenship, through their later stages of "engaged", "innovative" and "integrated" corporate citizenship. Reaching the fifth or "transforming" stage of corporate citizenship remains a future opportunity for Australia. Table 1 summarizes key characteristics of the five developmental stages of corporate citizenship in responsible gambling by drawing on some of Mirvis and Googins' (2004) underlying concepts. The following analysis tracks these developments in Australia from a macro view of general industry trends; practices of individual gambling providers have sometimes varied from this overarching pattern.

\section{Elementary stage}

In the mid-1990s, the Australian gambling industry was at the elementary stage of responsible gambling. As evidenced by many papers at the first national conference on responsible gambling (e.g., Brading, 1998; Hing, 1998; McMillen, 1998), expansionary government policies and intense competition meant gambling providers had given scant attention to responsible gambling. Policies and practices were undeveloped, industry leaders were defensive or uninterested, and little direct dialogue had occurred with pressure groups. Gambling operators were concerned that socially responsible practices were at odds with economic performance. If it was acknowledged, responsible gambling simply meant legal compliance. Further, gambling regulation had not yet embraced responsible gambling, except with respect to keeping gambling free from criminal elements and away from minors.

However, as new societal expectations emerge, mere legal compliance threatens the credibility of an organization or industry if they prove unwilling or unable to respond (Mirvis \& Googins, 2004). Problem gambling was a significant public health issue by this time and some triggers in the late 1990s began to threaten the industry's reputation. In New South Wales (NSW), Australia's most populous state, with the most extensive gambling facilities, the state government announced its first inquiry into gambling (Independent Pricing and Regulatory Tribunal of NSW, 1998). Also in 1998, the Federal Treasurer responded to public protests about gambling-related social problems and asked the Productivity Commission to conduct a wide-ranging inquiry into Australia's gambling industries (McMillen \& Wright, 2008). These events embedded "responsible gambling" firmly in the lexicon and helped shift corporate citizenship around gambling into the "engaged" stage (Mirvis \& Googins, 2004). 


\section{Engaged stage}

By 1997-1998, some gambling industry sectors were becoming engaged with responsible gambling, but their approach also typified the reactive and public relations-driven response generally found at this stage of corporate citizenship (Mirvis \& Googins, 2004).

For example, the Registered Clubs Association of NSW (RCA), representing the largest Australian sector providing machine gambling, was preparing for a selfregulatory responsible gambling policy, mandated by the Liquor and Registered Clubs Amendment (Community Partnership) Act 1998 NSW. While this shifted the clubs' social responsibilities into the legal arena, it relied on the RCA's preferred approach of industry self-regulation, with considerable latitude to determine the industry's responsible gambling measures and how they would be implemented, monitored and enforced.

However, a trial program revealed substantial venue reticence. Although the 19 trial clubs had volunteered to participate, most achieved only "minimum compliance" (Australian Institute for Gambling Research, 1998). Further, passive practices including signage, best practice guidelines, nomination of a club community liaison officer and self-exclusion, were most frequently endorsed, with far less willingness shown to implement harder measures that might threaten gambling income. These harder measures included responsible marketing strategies, barring credit withdrawals and providing deposit facilities on ATMs, imposing withdrawal limits on ATMs and EFTPOS, locating them outside gambling areas, imposing specific limits on cheque cashing and cash prize payments, altering the gambling environment and implementing venue intervention strategies to more proactively assist problem gamblers in the venue (Australian Institute for Gambling Research, 1998). The trial evaluation concluded that under a self-regulatory approach, not all clubs would comply due to:

- lack of agreement about the central aims and standards of responsible gambling;

- $\quad$ lack of effective deterrents for irresponsible practices;

- a strong economic incentive to not comply; and

- $\quad$ high resistance to change (Australian Institute for Gambling Research, 1998).

Some individual clubs had implemented responsible gambling programs before the RCA trial, but again these programs comprised passive measures that did not threaten competitiveness. Case studies of six of these programs revealed that the most widely implemented measures were signage and brochures (Hing, 2009). The second most common measure was self-exclusion, although its effectiveness was limited by lack of written agreements, time-frames, "cooling-off" periods for re-entry, involvement of counselors or publicity. Few initiatives attempted to limit access to cash for gambling, restrict advertising and promotions or to train staff. The six club programs evaluated had not progressed greatly beyond symbolic actions to improve their image. Substantive actions to reduce or prevent problem gambling received low priority.

At this time, a national picture of responsible gambling programs and practice was captured in an audit of measures (Hing, Mackellar, \& Dickerson, 2001). Mandated measures across jurisdictions were diverse, with bans on providing credit 
for gambling and providing gambling to minors being the only common measures. The audit identified 30 voluntary codes of practice, but their implementation was severely limited, with no effective monitoring and compliance mechanisms. The report concluded that: "jurisdictions and industry stakeholders have typically acted independently and in a 'knee-jerk' manner to increasing expressions of community concern about problem gambling" (Hing, Mackellar, \& Dickerson, 2001, p. ii).

The report also criticized these efforts for:

1. failure to draw upon existing literature on harm minimization as it relates to other leisure/ pleasure products that impinge on public health;

2. failure to develop strategies based on established principles or causal themes in the research literature; and

3. avoiding targeting those most at risk (Hing, Mackellar, \& Dickerson, 2001).

Thus, the engagement stage in responsible gambling was characterized by codes of practice with few effective implementation mechanisms, passive measures that did not threaten gambling revenues, reactive responses to community concerns, and symbolic actions focused more on protecting the industry's reputation than addressing gambling harms.

However, several triggers in 1999 prompted an industry shift to the next phase of corporate citizenship — the innovative stage (Mirvis \& Googins, 2004). One key trigger was the report of the national inquiry into gambling (Productivity Commission, 1999), which emphasized problem gambling and how it could be addressed. Its conclusions about the strong relationship between problem gambling and gaming machines, the need for harm minimization and consumer protection measures, and the inherent deficiencies of a self-regulated approach, drew further public attention to the social responsibilities of gambling operators and government. Further, the NSW Gaming Inquiry (Independent Pricing and Regulatory Tribunal of NSW, 1998) also advocated more proactive harm minimization and consumer protection strategies, enforced by legislation.

\section{Innovative stage}

Although many industry groups resisted the Productivity Commission's criticisms, governments responded quickly and a "new regulatory paradigm" began to emerge (McMillen \& Wright, 2008, p. 280). This ushered in genuinely new business practices, although resistance was still strong in many quarters (McMillen \& Wright, 2008).

The Legislation Amendment (Responsible Gambling) Act 1999 NSW operationalized recommendations of the NSW Gaming Inquiry for: minimum signage; staff training; self-exclusion; labelling, signage and brochure requirements; responsible advertising and promotions; enforcing the credit ban; responsible payment of winnings; and how to respond to a patron suffering gambling-related distress (Independent Pricing and Regulatory Tribunal, 1998, p. 44). This pioneered the first comprehensive, whole of industry responsible gambling legislation in Australia. Similar legislation was soon passed in most other Australian jurisdictions, with many inserting specific harm minimization objectives into gambling policy and legislation.

A different approach was pursued in Queensland, however. A voluntary responsible gambling Code of Practice was developed in 2002. This committed 
gambling providers to numerous practices in six areas - provision of information, interaction with customers and the community, exclusion provisions, physical environments, financial transactions and advertising (Queensland Treasury, 2002). Each industry sector developed comprehensive resource manuals to support the code's implementation. While research by the Queensland Government itself $(2004,2008)$ has generally found strengthening commitment to the code, lower commitment has been found among the hotel and club sectors compared to the casino, lottery and off-course betting sectors; among smaller organizations; in certain geographical areas; and for some practices. Nevertheless, despite its voluntary nature, independent empirical evidence (Breen, Buultjens, \& Hing, 2003; Hing \& Nuske, 2009) confirms industry practices have substantially changed since the code's introduction.

The preceding examples illustrate the innovative stage of corporate citizenship, when a swathe of new business practices was introduced. Some required alterations to existing business practices, such as moving ATMs outside of gaming rooms, inserting responsible gambling messages into gambling advertising, payment of large gambling winnings by cheque, and ending tray service of alcohol to players at gaming machines. Others were genuinely new practices, such as selfexclusion, and staff training in responsible gambling. Implementing these measures necessitated increased interaction of gambling operators with diverse stakeholders as they grappled to systematize, coordinate and manage these new activities. Support was typically provided by governments which produced minimum signage, local counseling agencies which supplied contact cards, industry associations which organized responsible gambling training and resource materials, and private consultants and trainers.

However, although this period heralded new business practices, these were sometimes introduced to the letter rather than spirit of the law or, if voluntary, not introduced at all. Indeed, McMillen \& Wright (2008) has described how a major constraint on reform at this time was the effective mobilization of the NSW gaming sector to defeat initiatives that conflicted with its economic interests. It was not until the next phase of corporate citizenship that responsible gambling became embedded in business practice and organizational culture.

\section{Integrated stage}

By the late 2010, responsible gambling had largely been incorporated into gambling business strategy and operations, and it was supported by integrative structures, processes and systems. This was partly a cultural shift, whereby after a decade of responsible gambling practices, these practices had become a normal part of business. It also reflected increased requirements expected or required of gambling operators.

In Queensland, the voluntary code of practice contained a commitment to regularly evaluate its progress. One evaluation of the accompanying cultural shift concluded: "there is a demonstrable increase in commitment to the code by key stakeholders. This suggests a shift towards embedding responsible gambling practices as a basic feature of running a gambling business" (Queensland Government, 2008, p. 9). As indicators, the report cited abatement of previously 
expressed impediments, such as distrust of gambling-related support services and concerns about the effectiveness and cost of implementing the code (Queensland Government, 2008, p. 9).

Other indicators of integration can be seen currently in the internal structures of organizations. Even many smaller venues now have responsible gambling customer liaison officers. Larger venues have responsible gambling managers, who typically develop the organization's responsible gambling policy, implement associated practices, organize staff training, vet marketing materials and liaise with key stakeholders. A second tier of supervision has emerged. Some Queensland casinos have Responsible Gambling Liaison Officers. They are the contact for staff approached by patrons seeking assistance for a gambling-related problem or who encounter patrons displaying problem gambling behaviors, and are trained in advising patrons about gambling help services and self-exclusions. They also observe patron behavior in the venue and report and act on problem gambling incidents (Hing \& Nuske, 2009).

Other indicators of a cultural shift are new and stronger relationships between gaming venues and local gambling help agencies. In some states, agencies provide venues with printed materials about local services, are a contact for venues for advice and patron referral, help organize patron self-exclusions, advise on specific situations, and provide staff training sessions (Hing \& Nuske, 2009; Hing, Nisbet, \& Nuske, 2010). This interaction provides professional "back-up", where agency staff can advise venue personnel on how to best deal with problem gamblers and how to improve venue practices. Once agency staff are known to venue personnel, the latter appear more likely to refer patrons to the agency or to get agency staff involved in supporting patrons of concern. This lowers barriers for patrons to attend counseling (Hing \& Nuske, 2009; Hing et al., 2010). Counselor input into staff training has also helped "humanize" problem gambling and convey its serious impact (Hing \& Nuske, 2009; Hing et al., 2010). The input of local gambling help agencies can assist venue staff to understand problem gambling, and to develop skills in listening, communicating, responding and approaching patrons of concern in a non-confrontational, supportive way.

Further embedding of responsible gambling into normal business practice is evidenced through regional responsible gambling committees and events. Public reporting of venue responsible gambling practices is now common. Some organizations have embedded responsible gambling into their mission statement, and some have sought external certification of their social responsibility in gambling.

Increased legal requirements have also helped integrate responsible gambling into the core business of gambling. Several Australian jurisdictions have now mandated responsible gambling staff training, and this training is required of all staff in casinos. Thus, responsible gambling is now considered an activity that should pervade the organization. Similarly, a revised mandatory code of practice in South Australia (Independent Gambling Authority, 2008) now requires internal reporting of suspected problem gamblers' details and interventions undertaken. This heightens venue and staff responsibility and reinforces the code's potential as a within-venue problem gambling management tool (Hing et al., 2010).

The above examples are all indicators of an integrated stage of corporate 
citizenship (Mirvis \& Googins, 2004). In Australia, responsible gambling is now embedded in organizational culture, structures, systems, processes and practices, rather than being an add-on function of the organization.

\section{Transforming stage}

Several pressures may push the Australian gambling industry towards the fifth stage of corporate citizenship - the transforming stage - where organizations "change the game", bring about social change or otherwise transform the core business by fusing their citizenship and business agendas (Mirvis \& Googins, 2004, p. 108). Two key drivers can be identified - the Productivity Commission's second national gambling inquiry (2010) and technological advancements. Both may prove catalysts for more proactive, effective and targeted responsible gambling measures.

The Productivity Commission (2010) has left little doubt that, even after a decade of responsible gambling, gaming machine operators draw a sizeable proportion of revenue from players facing significant risks with their gambling. It concluded that: "a more coherent and effective policy approach is needed, with targeted policies that can effectively address the high rate of problems experienced by those playing gaming machines regularly" (Productivity Commission, 2010, p. 2). The Commission (2010) has recommended some sweeping changes, including:

- that the bet limit be lowered from AUD\$10 to AUD\$1 per button push;

- $\quad$ much lower limits (AUD\$20) on how much cash can be inserted into machines at any one time;

- $\quad$ longer gaming room shutdown periods;

- lower daily cash withdrawal limits on ATMs to AUD\$250;

- $\quad$ more conspicuous and market-tested warning messages;

- $\quad$ payment of gambling prizes above AUD $\$ 300$ by check or direct debit;

- jurisdiction-wide self-exclusion programs;

- $\quad$ stronger monitoring of venue compliance;

- $\quad$ statutory provisions to enable gamblers to seek redress through the courts for "egregious behavior" by venues; and

- a progressive move over six years to a universal precommitment system that allows all gaming machine players in all venues to set binding limits on their future play.

The Commission noted that:

Adoption of new technologies may expand the appeal of gaming machines and their use by recreational gamblers, partly offsetting the revenue losses associated with more stringent harm minimization. Indeed, under new regulatory arrangements, innovation would be strongly targeted at achieving that end. (2010, p. 30).

Clearly, the Productivity Commission (2010) is pressuring for more effective responsible gambling measures that proactively target problem and at-risk gamblers, even if these measures are costly to industry and government revenue.

At the time of writing, it is unclear when, and if, the Productivity Commission's (2010) recommendations will be implemented. However, given its first national gambling inquiry (1999) prompted a shift from the elementary stage of corporate citizenship to the engaged stage and beyond, the 2010 inquiry may have a profound 
impact on how gambling operators do business. A transforming stage might ultimately be characterized by revenue derived solely from non-problem gamblers, mechanisms to ensure gamblers do not lose control over the time and money they spend on gambling, and prevention of the harms associated with gambling problems. Such a shift would indeed transform the industry and also Australian society.

\section{Discussion: Insights for Asian Jurisdictions}

Organizations are propelled through stages of corporate citizenship in a normative trajectory by a series of triggers arising from tensions between current practices and the problems they produce; and that demand a fresh organizational response (Mirvis \& Googins, 2004). However, varying social, economic, cultural, political and institutional forces shape this trajectory in different ways. Some similarities and differences between Asia and Australia likely to affect the evolution of responsible gambling in Asia are now considered.

Akin to the Australian experience during the 1970-1990s, many Asian countries are now experiencing an unprecedented expansion in commercial gambling. In Macau, the pace and scale has been extraordinary, but even Singapore's more modest expansion has introduced new forms of gambling to its residents. In Korea, residents have had access to casino gambling since 2000. This expansion and the introduction of new gambling activities suggest that problem gambling will continue to emerge as a significant social and public health issue, both within these countries and in their market-generating areas.

As in Australia, expansionary government policies will likely attract criticism from some quarters, given the decision to liberalize gambling rests with governments. However, a large burden of remedial measures to prevent or minimize harm from gambling will fall on gambling operators, as they are the visible manifestation of gambling liberalization and are at the interface between the gambling product and the gambler. Indeed, it is noteworthy that multinational casino operators have been the first to introduce responsible gambling measures in Asia. These larger operators tend to be at a more advanced stage of corporate citizenship in relation to gambling, given their long experience in countries where gambling expansion preceded the current growth of gambling in Asia.

The Australian experience also suggests that industry self-regulation of responsible gambling practice has very limited success and tends to be undermined by lack of deterrents for irresponsible practices, strong financial incentives that run counter to responsible gambling initiatives, and resistance to change. This is evidenced in Macau, where minimal responsible gambling legislation has resulted in minimal responsible gambling measures, especially in the locally owned establishments. There, self-regulation has yielded passive, symbolic measures, mainly comprising signage. In contrast, more stringent legislation in Singapore has led to more rigorous responsible gambling measures.

Even where regulated, responsible gambling requires time for a cultural shift to occur so that it is truly integrated into business strategy and operations. In Asia, this integration also appears necessary for gambling providers to be truly committed to the spirit and not just the letter of responsible gambling measures. 
Further, substantial leadership, resources and support mechanisms outside of the organization can provide a real boost to effective implementation, as can effective relationships with key stakeholders. Thus, industry associations, government, the community services sector, pressure groups, gambling researchers and local authorities in the region can all help to shift corporate citizenship towards the socially responsible end of the scale.

Changes internal to the organization are also required. As well as new business practices, embedding responsible gambling into the business of gambling can be greatly facilitated by structural changes, dedicated management and supervisory positions, staff training, responsible gambling events, accountability and transparent reporting. Some of these features have been introduced in some Asian casinos, but are typically not as extensive as found in their Australian counterparts.

Research is also needed to identify the most effective responsible gambling measures that target problem and at-risk gamblers, without unduly affecting recreational gamblers, and without imposing unnecessary costs on industry and government. Various government inquiries and a sustained research effort in Australia have been crucial in prompting the gambling industry along the stages of corporate citizenship. Conversely, a major impediment in some Asian jurisdictions, such as Macau, is lack of evidence about the effectiveness of various responsible gambling measures in the local context. Where corporate citizenship is elementary, lack of evidence about the problems caused by gambling and about the efficacy of preventative and remedial measures provides little impetus for organizational change.

Whether Asia will follow the same trajectory as Australia in relation to responsible gambling remains to be seen. Some differing conditions will be influential. For example, some Asian countries have opted for destination-style gambling, clustering gambling establishments in limited precincts and targeting revenues generated from tourist markets. Some have imposed controls on local access, such as requiring a foreign passport and banning entry by domestic government employees. Others have attempted to deter people of limited financial means, by charging a sizeable entry fee or refusing entry to those in receipt of welfare payments. Cultural differences in both the market and the management of gambling operations will also be influential. A major difference is the popularity of table games in Asia, where responsible gambling measures developed for the gaming machine market in countries like Australia may not be appropriate. Further, reliance of jurisdictional governments on gambling taxes varies enormously and is likely to affect the extent of responsible gambling legislation imposed.

Despite these differences, Asian countries may benefit through a process of policy-learning from jurisdictions like Australia. Australia has not only experienced the emergence of problem gambling as a serious public health issue but has also seen the transition of responsible gambling policy and practice from an elementary stage of corporate citizenship, through to its integration into gambling business practice. It is hoped that the Australian experience, as outline in this paper, can serve to usefully inform the future of responsible gambling throughout Asia. 


\section{References}

Apostel, L. (1961). Towards the formal study of models in the non-formal sciences. In H. Freudenthal (Ed.), The concept and role of the model in mathematics and natural and social sciences (pp. 1-37). London: Springer.

Australian Institute for Gambling Research. (1998). The responsible gambling trial program for NSW registered clubs. Sydney: Registered Clubs Association of NSW.

Barnard, C. I. (1938). The functions of the executive. Cambridge: Harvard University Press.

Blaszczynski, A., Ladouceur, R., \& Shaffer, H. J. (2004). A science-based framework for responsible gambling: The Reno model. Journal of Gambling Studies, 20(3), 301-317.

Brading, R. (1998). Harm minimisation strategies in NSW and law reforms. In G. Coman, B. Evans, \& R. Wootton (Eds.), Responsible gambling: A future winner. Proceedings of the Eighth National Conference of the National Association for Gambling Studies (pp. 26-34). Melbourne: National Association for Gambling Studies.

Breen, H., Buultjens, J., \& Hing, N. (2003). The perceived efficacy of responsible gambling strategies in Queensland hotels, casinos and licensed clubs. Report commissioned by the Research and Community Engagement Division of Queensland Treasury. Lismore: Centre for Gambling Education and Research.

Charlton, P. (1987). Two flies up a wall: the Australian passion for gambling. Sydney: Methuen Haynes.

Connor, F. X. (1983). Report of Board of Inquiry into casinos. Melbourne: Victorian Government.

Hing, N., \& Nuske, E. (2009). Assisting problem gamblers in the gaming venue: An assessment of responses provided by frontline staff, customer liaison officers and gambling support services to problem gamblers in the venue. Report commissioned by the Queensand Office of Gaming Regulation. Lismore: Centre for Gambling Education and Research.

Hing, N. (1998). Responsible gambling in NSW clubs: Perceptions, prospects and problems. In G. Coman, B. Evans, \& R. Wootton (Eds.), Responsible gambling: A future winner. Proceedings of the Eighth National Conference of the National Association for Gambling Studies (pp. 164-179). Melbourne: National Association for Gambling Studies.

Hing, N. (2002). The emergence of problem gambling as a corporate social issue in Australia. International Gambling Studies, 2, 101-122.

Hing, N. (2009). Changing fortunes: Past, present and future perspectives on the management of problem gambling by New South Wales clubs. Saarbrucken: VDM Publishing.

Hing, N., Mackellar, J., \& Dickerson, M. (2001). Australian Gaming Council detailed responsible gambling document. Melbourne: Australian Gaming Council.

Hing, N., Nisbet, S., \& Nuske, E. (2010). Assisting problem gamblers in South Australian gaming venues. Report commissioned by the Independent Gambling Authority of South Australia. Lismore: Centre for Gambling Education and Research.

Independent Gambling Authority. (2008). Responsible gambling code of practice. Adelaide: South Australian Government.

Independent Pricing and Regulatory Tribunal of NSW (IPART). (1998). Report to government: Inquiry into gaming in NSW. Sydney: Independent Pricing and Regulatory Tribunal of NSW.

Lusher, E. A. (1977). Report on the inquiry into the legalization of gambling casinos in New South Wales. Report to the NSW Premier. Sydney: NSW Government.

Mahon, J. F., \& Waddock, S. A. (1992). Strategic issues management: An integration of issue lifecycle perspectives. Business and Society, 31(1), 19-32.

McMillen, J. (1994). The state and gambling: Social benefit or milch cow? In N. Ryan \& P. Walsh (Eds.), Bridging the divide (pp. 70-83). Brisbane: Queensland Economics and Social Policy, Queensland Council of Social Services.

McMillen, J. (1996a). Introduction. In J. McMillen (Ed.), Gambling cultures: Studies in history and 
interpretation (pp. 1-5). London: Routledge.

McMillen, J. (1996b). Perspectives on Australian gambling policy: Changes and challenges. Paper presented at the National Conference on Gambling. Sydney.

McMillen, J. (1997). When gambling is a problem - implications for public health. Consumer Rights Journal, 1(3), 10-14.

McMillen, J. (1998). Market competition: A sound foundation for gambling policy? In G. Coman, B. Evans, \& R. Wootton (Eds.), Responsible gambling: A future winner. Proceedings of the Eighth National Conference of the National Association for Gambling Studies (pp. 247-258). Melbourne: National Association for Gambling Studies.

McMillen, J., \& Wright, J. S. F. (2008). Re-regulating the gambling industry: Regulatory reform in Victoria and New South Wales, 1999-2006. Australian Journal of Political Science, 43(2), 277-300.

Mirvis, P., \& Googins, B. (2004). Stages of corporate citizenship. California Management Review, 48(2), 104-126.

Moffitt, A. R. (1974). Report of the Honourable Mr Justice Moffitt, Royal Commissioner appointed to inquire in respect of certain matters relating to allegations of organized crime in clubs. Sydney: Government Printer.

Productivity Commission. (1999). Australia's gambling industries (Report No. 10). Canberra: AusInfo.

Productivity Commission. (2010). Gambling (Report No. 50). Canberra: Commonwealth of Australia.

Queensland Government. (2004). Queensland responsible gambling code of practice: Report on the implementation review. Brisbane: Queensland Government.

Queensland Government. (2008). Queensland responsible gambling code of practice: Report on the cultural shift review. Brisbane: Queensland Government.

Queensland Treasury. (2002). Queensland responsible gambling code of practice: Trial and review. Brisbane: Queensland Government.

Street, L. (1991). Inquiry into the establishment and operation of legal casinos in New South Wales. Report to the Chief Secretary and Minister for Administrative Services in the NSW State Government. Sydney: NSW Government.

Sylvan, R., \& Sylvan, L. (1985). The ethics of gambling. In G. Caldwell, B. Haig, M. Dickerson, \& L. Sylvan (Eds.), Gambling in Australia (pp. 217-231). Sydney: Croomhelm Australia Pty Ltd.

Tasmanian Gaming Commission. (2000). Australian gambling statistics 1973-74 to 1998-99. Hobart: Tasmanian Gaming Commission.

Volberg, R. A. (1998). Prevalence research and the evolution of responsible gambling. In G. Coman, B. Evans, \& R. Wootton (Eds.), Responsible gambling: A future winner. Proceedings of the Eighth National Conference of the National Association for Gambling Studies (pp. 390-395). Melbourne: National Association for Gambling Studies.

Wartick, S. L., \& Mahon, J. F. (1994). Toward a substantive definition of the corporate issue construct. Business and Society, 33(3), 293-311.

Wilcox, M. (1983). Report of board of inquiry into poker machines. Melbourne: Victorian Government Printer. 